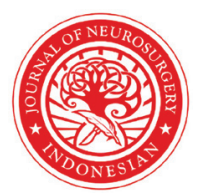

Indonesian Journal of Neurosurgery

\section{Correlation of vestibular schwannoma tumor with facial nerve weakness, hypoesthesia of face, and disequilibrium}

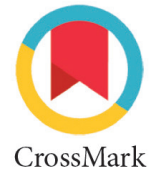

CrossMark

\author{
Agung Budi Sutiono', Selfy Oswari', Centery ${ }^{1 *}$
}

'Skull Base Division, Department of Neurosurgery, Hasan Sadikin General Hospital, Universitas Padjadjaran;

*Corresponding author:

Centery;

Skull Base Division, Department of Neurosurgery, Hasan Sadikin General Hospital, Universitas Padjadjaran; centery_lee@yahoo.com

Received: 2021-06-04 Accepted: 2021-10-22

Published: 2021-12-03

\section{ABSTRACT}

Introduction: Vestibular schwannoma is the most common lesion in the cerebellopontine angle. Some of the most common symptoms arise as the tumor grows bigger such as disequilibrium, hypoesthesia of the face, and facial nerve paresis. Based on the American Academy of Otolaryngology-Head and Neck Surgery (AA0-HNS) and the Consensus Meeting on Systems for Reporting Results in Acoustic Neuroma, there is still no clarity of a single method used to measure the tumor itself.

Methods: This was a retrospective study to analyze the correlation between the size (anteroposterior and mediolateral) of the vestibular schwannoma with disequilibrium, hypoesthesia of the face, and facial nerve paresis among the patients in the Neurosurgery Department of Hasan Sadikin Hospital Bandung from January 2014 to December 2019. The data was analyzed using Spearman and Binary Logistic Regression.

Results: A total of 58 patients were included in this study with median age was 43 years, ranging from $21-72$ years. The most common symptoms were disequilibrium (48.27\%), followed by facial nerve paresis (39.65\%) and hypoesthesia of face (20.68\%). The mean anteroposterior size was $3.8 \pm 1.17 \mathrm{~cm}$ and the mean mediolateral size was $3.0 \pm 1.01 \mathrm{~cm}$. There were significant correlation between disequilibrium with anteroposterior size $(r=0.385 ; p=0.003)$ and mediolateral size $(r=$ $0.409 ; p=0.001)$. There were also significant correlation between facial nerve paresis with anteroposterior size $(r=0.458$; $p=0.000)$ and mediolateral size $(r=0.321, p=0.014)$.

Conclusion: There were significant correlations between the anteroposterior and mediolateral size of the tumor with the occurrence of disequilibrium and facial nerve paresis in patients with vestibular schwannoma.

Keywords: diameter, disequilibrium, facial nerve paresis, hypoesthesia of the face, vestibular schwannoma.

Cite This Article: Sutiono, A.B., Oswari, S., Centery. 2021. Correlation of vestibular schwannoma tumor with facial nerve weakness, hypoesthesia of face, and disequilibrium. Indonesian Journal of Neurosurgery 4(3): 94-97. D0I: 10.15562/ijn. v4i3.149

\section{INTRODUCTION}

Vestibular schwannoma is the most common lesion in the cerebellopontine angle (CPA) and reaches almost $75 \%$ of all lesions in this area. Vestibular schwannoma arises from the inferior division of the vestibular nerves. Three common earlier symptoms include loss of hearing (insidiously and progressive), tinnitus, and disequilibrium. A bigger tumor can cause numbness of the face, weakness of the face, and even symptoms related to the pressure of the brain stem or hydrocephalus. ${ }^{1}$

Aside from the loss of hearing, most of the patients who came to our hospital at Hasan Sadikin Hospital showed symptoms like disequilibrium, numbness, and weakness of the face. Otalgia, weakness, and numbness of the face occur as the tumor grows bigger and presses the trigeminal and facial nerves. A unique paradox is that weakness of the face is less frequent even it is always distorted since early; compared to numbness of the face that always occurs as it is squeezed. This phenomenon is thought of as motoric nerve more resist than sensory nerve. ${ }^{1}$ Huang et al. stated that most experts defined this tumor only by one dimension in measuring the size, for example, the diameter $>3 \mathrm{~cm}$, although the volume itself would vary, as the diameter $3 \mathrm{~cm}$, the volume could be 4.3 until $17.3 \mathrm{~cm}^{3}$, ranging from 1.34 to $25.2 \mathrm{~cm}^{3}$. $^{2}$

Total tumor excision with preservation of the neurologic function and quality of life is the goal of vestibular schwannoma surgery. Recognizing the course of the facial nerve related to the tumor in the preoperative stage is valuable for the surgeon. ${ }^{3}$ Identification of facial nerve perhaps can be accomplished with 3 dimensions multiplanar Magnetic Resonance Imaging (MRI), but impossible with conventional MRI. ${ }^{4}$ It is almost impossible to visualize or predict the anatomy of the cranial nerve displaced preoperatively with the current diagnostic technique, especially in large vestibular

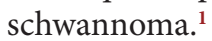

Some standard methods to report and measure tumors have been suggested by some national organizations, such as the American Academy of OtolaryngologyHead and Neck Surgery (AAO-HNS) in 1995 and the Consensus Meeting on Systems for Reporting Results in Acoustic Neuroma in 2003, but no single method is 
clearly utilized. ${ }^{3}$

Vestibular schwannoma needs to be described as intracanalicular, extrameatal or intra-meatal. The growth of

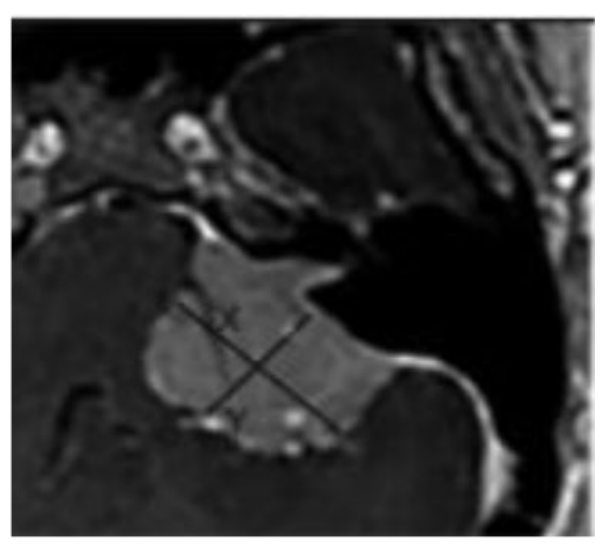

Figure 1. Measurement of extra-meatal vestibular schwannoma according to AAO-HNS. tumors tends to be dominant at extrameatal and some recommendations focus on measuring extra-meatal. AAOHNS recommended using extra-meatal anteroposterior diameter (parallel with petrous ridge) multiply with the mediallateral diameter (Fig. 1). ${ }^{3}$ Otherwise, the consensus meeting in 2003 prefer to measure the maximum extra-meatal diameter.

\section{METHODS}

This was a retrospective study evaluating vestibular schwannoma patients who preoperatively came to our hospital from 2014 until 2019. We defined the size of the tumor as the independent variable, while facial nerve paresis, numbness of the face, and disequilibrium as dependent variables.
Samples were grouped based on their symptoms, which were disequilibrium, hypesthesia of the face, and facial nerve paresis. The size of the tumor was measured with the AAO-HNS method. Data collected were analyzed to determine the correlation between the size of vestibular schwannoma and the symptoms of facial nerve paresis, hypesthesia of the face, and disequilibrium. The operational definition of the variable can be seen in Table 1 .

\section{RESULTS}

\section{Size of tumor and symptoms}

As can be seen in Table 2, the mean age of the subjects was $43.53 \pm 12.56$ years old. There were 26 males $(44.8 \%)$ and 32 females (55.2\%). The most common symptom was disequilibrium (48.27\%) and was followed by facial nerve paresis

Table 1. Operational definition of the variable included in this study.

\begin{tabular}{|c|c|c|}
\hline Variable & Operational Definition & Measure scale \\
\hline Size of tumor & $\begin{array}{l}\text { Tumor in CPA area, cystic/solid. Scale on CT scan/MRI, measure in anteroposterior } \\
\text { and mediolateral diameter. }\end{array}$ & Nominal \\
\hline Hypesthesia of the face & Numbness of the face. No other cause than the tumor. & Categorical \\
\hline Facial nerve paresis & Weakness of the face. No other cause than the tumor. & Categorical \\
\hline Disequilibrium & Inability to maintain equilibrium, with Romberg test. No weakness of extremities & Categorical \\
\hline
\end{tabular}

CPA: Cerebellopontine angle; CT: Computed tomography; MRI: Magnetic resonance imaging

Table 2. Characteristic of samples.

\begin{tabular}{|c|c|c|}
\hline Characteristic & Sample (N) & Value (percentage) \\
\hline \multicolumn{3}{|l|}{ Demography } \\
\hline Age (years) & 58 & \\
\hline Mean \pm SD & & $43.53 \pm 12.56$ \\
\hline Median & & 43 \\
\hline Min - max & & $21-72$ \\
\hline Gender & 58 & \\
\hline Male & & $26(44.8)$ \\
\hline Female & & $32(55.2)$ \\
\hline Symptoms & 58 & \\
\hline Disequilibrium & & $28(48.27)$ \\
\hline Hypesthesia of face & & $12(20.68)$ \\
\hline Facial paresis & & $23(39.65)$ \\
\hline Size of tumor $(\mathrm{cm})$ & 58 & \\
\hline \multicolumn{3}{|l|}{ Anteroposterior } \\
\hline Mean \pm SD & & $3.8 \pm 1.17$ \\
\hline Median & & 4 \\
\hline Min - max & & $2.63-4.97$ \\
\hline \multicolumn{3}{|l|}{ Mediolateral } \\
\hline Mean \pm SD & & $3.0 \pm 1.01$ \\
\hline Median & & 3 \\
\hline Min - max & & $1.99-4.01$ \\
\hline
\end{tabular}




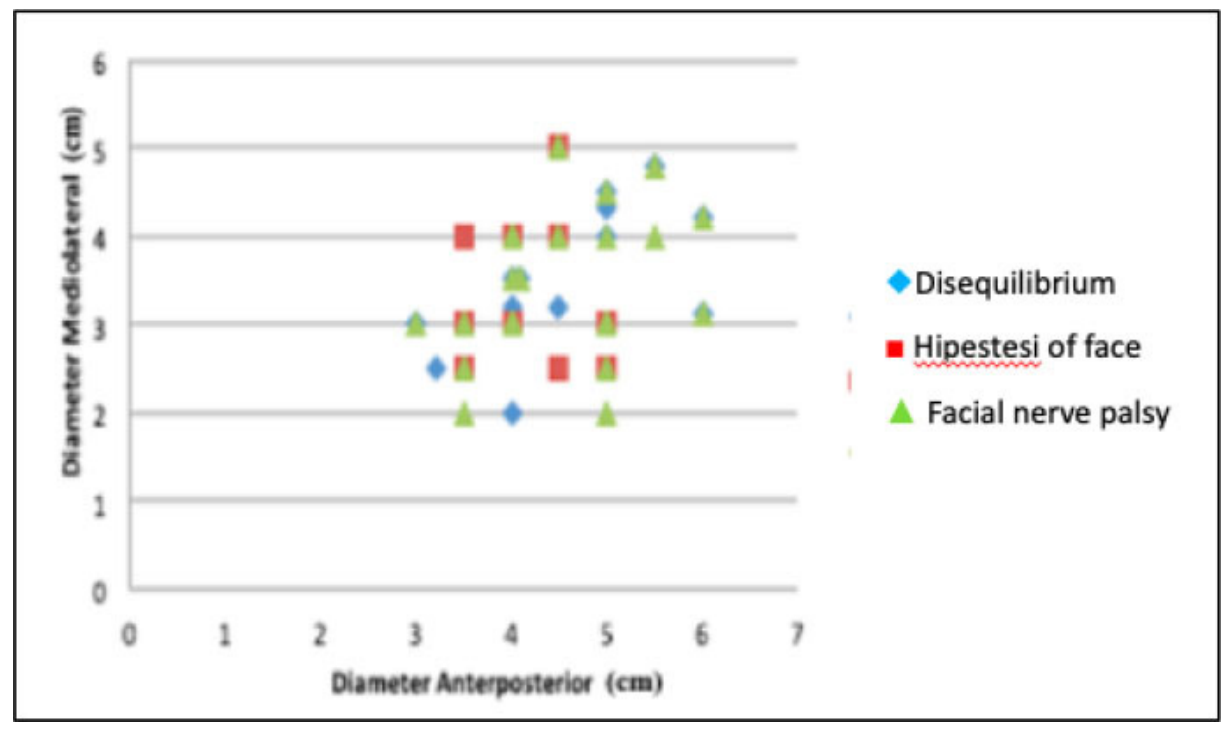

Figure 2. Distribution of symptoms related to the size of the tumor.

Table 3. Correlation between size of the tumor and symptoms.

\begin{tabular}{clcc}
\hline Size & \multicolumn{1}{c}{ Symptom } & r & P-value \\
\hline Anteroposterior & Disequilibrium & 0.385 & 0.003 \\
& Hypesthesia of face & 0.137 & 0.305 \\
& Facial nerve paresis & 0.458 & 0.000 \\
Mediolateral & Disequilibrium & 0.409 & 0.001 \\
& Hypesthesia of face & 0.102 & 0.448 \\
& Facial nerve paresis & 0.321 & 0.014 \\
\hline
\end{tabular}

Table 4. Causal correlation of size and symptoms.

\begin{tabular}{clc}
\multicolumn{1}{c}{ Size } & \multicolumn{1}{c}{ Symptom } & P-value \\
\hline Anteroposterior & Disequilibrium & 0.004 \\
& Hypesthesia of face & 0.271 \\
& Facial nerve paresis & 0.002 \\
\multirow{2}{*}{ Mediolateral } & Disequilibrium & 0.009 \\
& Hypesthesia of face & 0.302 \\
& Facial nerve paresis & 0.021 \\
\hline
\end{tabular}

Table 5. Predicting symptoms based on the size of the tumor.

\begin{tabular}{ccc}
\hline Symptom & Accuracy (\%) & P-value \\
\hline Disequilibrium & 67.2 & 0.002 \\
Hypesthesia of face & 79.3 & 0.466 \\
Facial nerve paresis & 70.7 & 0.001 \\
\hline
\end{tabular}

Table 6. Minimum size of the tumor for symptoms to occur.

\begin{tabular}{cccc}
\hline \multicolumn{2}{c}{ Disequilibrium } & \multicolumn{2}{c}{ Facial nerve paresis } \\
\hline $\mathbf{x}(\mathbf{c m})$ & $\mathbf{y}(\mathbf{c m})$ & $\mathbf{x}(\mathbf{c m})$ & $\mathbf{y}(\mathbf{c m})$ \\
\hline 6 & 1 & 5 & 1 \\
5 & 2 & 5 & 2 \\
5 & 3 & 5 & 3 \\
4 & 4 & 5 & 4 \\
3 & 5 & 5 & 5 \\
2 & 6 & 4 & 6 \\
\hline
\end{tabular}

$\mathrm{x}$ : anteroposterior diameter; $\mathrm{y}$ : mediolateral diameter and hypesthesia of the face, which were $39.65 \%$ and $20.68 \%$, respectively. The mean anteroposterior diameter was $3.8 \pm$ $1.17 \mathrm{~cm}$ while the mediolateral diameter was $3.0 \pm 1.01 \mathrm{~cm}$.

As can be seen in Fig. 2, disequilibrium and facial nerve paresis started to occur as early as the diameter of the tumor reached $3 \mathrm{~cm}$ and $2 \mathrm{~cm}$ in anteroposterior and mediolateral diameter, respectively. On the other hand, hypesthesia of the face occurred afterward.

\section{Correlation between size of tumor and symptoms}

The correlation between the size of the tumor and symptoms that occurred was analyzed using the Spearman test. Based on Table 3 below, there was a significant positive correlation between the size of the tumor, either anteroposterior or mediolateral diameter, with disequilibrium and facial nerve paresis. In order to know whether the size of the tumor has a causal correlation with the symptoms, we analyzed the data with Binary Logistic Regression as shown in Table 4, which showed a significant correlation between the size of the tumor with disequilibrium and facial nerve paresis, either in anteroposterior or mediolateral diameter.

Based on the correlation in Table 3 and Table 4, we tried to analyze the chance to predict the onset of the symptoms (disequilibrium, hypesthesia of the face, and facial nerve paresis) due to the size of the tumor. We utilized the Omnibus test to analyze the data as shown in Table 5 below.

As can be seen in Table 5 the anteroposterior and mediolateral diameter can predict disequilibrium and facial nerve paresis significantly, about $67.2 \%$ and $70.7 \%$, respectively. In Table 6 , we can see the prediction of the minimum size of the tumor to cause disequilibrium and facial nerve paresis.

\section{DISCUSSION}

This study included 58 subjects who fulfill the inclusion criteria. Based on demography characteristics, the median age was 43 years old, with a range of 21 72 years old, which was not different from previous studies. ${ }^{2,5-8}$ Twenty-six subjects (44.8\%) were male and 32 subjects $(55.2 \%)$ were female. Previous literature also 
reported no significant difference in sex predilection in vestibular schwannoma. ${ }^{7,9}$

Among the three symptoms, the most common symptom was disequilibrium (48.27\%) and was followed by facial nerve paresis (39.65\%) and hypesthesia of the face $(20.68 \%)$. This study has a similar result as previous studies which reported disequilibrium as the most common symptom, followed by hypesthesia of the face and facial nerve paresis. ${ }^{1,5,6}$ However, other studies also reported when the tumor reaches $1.5 \mathrm{~cm}$ in size, it would cause compression to the facial nerve, but usually asymptomatic, until hypesthesia of the face occurs first. ${ }^{1,4}$

In this study, the mean anteroposterior diameter of the tumor was $3.8 \pm 1.17 \mathrm{~cm}$, ranging from $2.63-4.97 \mathrm{~cm}$, mediolateral diameter of the tumor was $3.0 \pm 1.01 \mathrm{~cm}$, ranging from $1.99-4.01 \mathrm{~cm}$. This result was similar to previous studies about the symptomatic tumor, like the one studied by Ocak et al. ${ }^{5}$, with results of $3.0 \pm 1.12$ $\mathrm{cm}$, and Savardekar et al. ${ }^{7}$, with results $3.26 \pm 1.6 \mathrm{~cm}$. However, previous studies utilized only the maximum diameter of the tumor. Some authors, like Huang et al. and Schnurman et al., measure vestibular schwannoma in volumetric. ${ }^{2,10}$

In this study, the size of the anteroposterior and mediolateral diameter of the tumors had a significantly strong correlation with disequilibrium and facial nerve paresis. It means that bigger in size increases the chance of disequilibrium and facial nerve paresis occurrence. We also found that the symptoms started to occur when the anteroposterior and mediolateral diameter reach 3 and $2 \mathrm{~cm}$, respectively.

The main limitation of this study was the retrospective nature of the data analysis, which leads to potential ascertainment bias. Besides, the limited number of patients may have precluded a firm conclusion regarding the prediction of the size of the tumor and symptoms caused by its size. In addition, this study was not a randomized controlled trial, which is another limitation. Further studies with more cases and a control group are necessary to confirm our findings. Our results also reflected the findings in a single-center, which may not be representative of the neurosurgical cases in other large academic centers and may limit the generalizability of the data.

\section{CONCLUSION}

The sequence of the occurrence of the symptoms when the anteroposterior diameter reaches three centimeters was facial nerve paresis, disequilibrium, and hypesthesia of the face. On the other hand, once the mediolateral diameter reaches $2 \mathrm{~cm}$, the sequence was disequilibrium, facial nerve paresis, and hypesthesia of the face.

Once the earliest symptom is facial nerve paresis, the chance of the growth of the tumor is more likely in an anteroposterior direction. If the earliest symptom is disequilibrium, then the tumor is more likely to grow in the mediolateral direction, in which the tumor tends to compress the cerebellum and pons.

\section{FUNDING}

None.

\section{CONFLICTS OF INTEREST}

There are no conflicts of interest.

\section{AUTHOR CONTRIBUTIONS}

All authors contributed equally in preparing this manuscript.

\section{REFERENCES}

1. Greenberg S. Handbook of Neurosurgery. 8th ed. NewYork: Thieme; 2016.

2. Huang C-W, Tu H-T, Chuang C-Y, Chang C-S, Chou H-H, Lee M-T, et al. Gamma knife radiosurgery for large vestibular schwannomas greater than $3 \mathrm{~cm}$ in diameter. $J$ Neurosurg. 2018; 128(5): 1380 - 1387. https://doi. org/10.3171/2016.12.JNS161530.

3. Lin EP, Crane BT. The management and imaging of vestibular schwannomas. AJNR Am J Neuroradiol. 2017; 38(11): 2034 - 2043. https://doi.org/10.3174/ajnr.A5213.

4. Sartoretti-Schefer S, Kollias S, Valavanis A. Spatial relationship between vestibular schwannoma and facial nerve on threedimensional T2-weighted fast spin-echo MR Images. AJNR Am J Neuroradiol. 2000; 21(5): $810-6$.

5. Ocak PE, Dogan I, Ocak U, Dinc C, Baskaya MK. Facial nerve outcome and extent of resection in cystic versus solid vestibular schwannomas in radiosurgery era. Neurosurg Focus. 2018; 44(3): E3. https://doi.org/10.3171/2017.12. FOCUS17667.

6. Hoshide R, Faulkner H, Teo M, Teo C. Keyhole retrosigmoid approach for large vestibular schwannomas: Strategies to improve outcomes. Neurosurg Focus. 2018; 44(3): E2. https://doi. org/10.3171/2017.11.FOCUS17607.

7. Savardekar AR, Patra DP, Thakur JD, Narayan V, Mohammed N, Bollam P, et al. Preoperative diffusion tensor imaging-fiber tracking for facial nerve identification in vestibular schwannoma: A systematic review on its evolution and current status with a pooled data analysis of surgical concordance rates. Neurosurg Focus. 2018; 44(3): E5. https://doi. org/10.3171/2017.12.FOCUS17672.

8. Bae CW, Cho YH, Hong SH, Kim JH, Lee J-K, Kim CJ. The anatomical location and course of the facial nerve in vestibular schwannoma: A study of 163 surgically treated cases. J Korean Neurosurg Soc. 2007; 42(6): 450 - 454. https:// doi.org/10.3340/jkns.2007.42.6.450.

9. Link MJ, Kondziolka D, Samii M. Update on the treatment of acoustic tumors. Neurosurg Focus. 2018; 44(3): E1. https://doi. org/10.3171/2017.12.FOCUS17785.

10. Schnurman Z, Nakamura A, McQuinn MW, Golfinos JG, Roland JT, Kondziolka D. Volumetric growth rates of untreated vestibular schwannomas. J Neurosurg. 2019; 1 - 7. https:// doi.org/10.3171/2019.5.JNS1923.

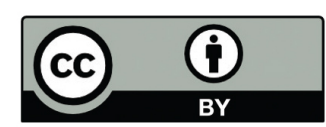

This work is licensed under a Creative Commons Attribution 